\title{
Penyuluhan Penggunaan dan Pencegahan Pengaruh Gadget di Rumah Tangga
}

\author{
Agus Salim \\ Pendidikan Agama Islam, STAI Syekh H. Abdul Halim Hasan Al Ishlahiyah Binjai \\ Jl. Ir. H. Juanda - Binjai \\ Email: agusasahan40@gmail.com
}

\begin{abstract}
This activity aims to increase understanding and knowledge about gadgets. Advances in Technology and Information affect many aspects of human life, including economics, laws, health, and education. The existence of technology provides convenience in various activities of humans; however, it replaces human labor too. Likewise, the advancement of digital-based information enables humans to access information from anywhere at any period, while the most current information moves quickly. The presence of Technology and Information must be accompanied by human ability. Ability to use well and filter information effectively. The sophistication of technology and the speed of information should be accompanied by the ability to use it, which aims to use various technological products in learning activities. Thus, teachers can teach using technology products such as e-books, animations, slides, and videos. However, humans have numerous opportunities to use technology products to make things that go against the good intentions of technological and information inventions. For this reason, before and while using technology and reading the information, every technology user must obtain an education.
\end{abstract}

\author{
Keywords \\ Gadget, technology, \\ education.
}
BERDAYA : Jurnal Pendidikan dan Pengabdian Kepada Masyarakat Vol 3, No.3, Desember 2021, pp. $111-116$ eISSN 2721-6381

\section{Article History}

Received 30 Nov 2021 / Accepted 14 Dec 2021 / First Published: 16 Dec 2021

To cite this article

Salim, A. (2021). Penyuluhan Penggunaan dan Pencegahan Pengaruh Gadget di Rumah Tangga. BERDAYA: Jurnal Pendidikan Dan Pengabdian Kepada Masyarakat, 3(3), 111 - 116.

DOI: $10.36407 /$ berdaya.v3i3.464

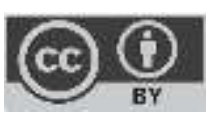

(C) The Author(s)2021

. This open access article is distributed under a Creative Commons Attribution (CC-BY) 4.0 license 


\begin{abstract}
ABSTRAK
Kegiatan ini bertujuan untuk menambah pemahaman dan pengetahuan ibu rumah tangga tentang gadgaet. Peluang dan tantangan teknologi dan informasi dalam pendidikan kemajuan teknologi dan informasi memberikan efek dalam berbagai aspek kehidupan manusia, di antaranya aspek ekonomi, hukum, kesehatan, dan pendidikan. Keberadaan teknologi memberikan kemudahan dalam berbagai aktivitas kehidupan manusia tetapi juga menggantikan pekerjaan manusia. Begitu juga kemajuan informasi berbasis digital memudahkan manusia untuk mengakses informasi dari manapun sedangkan informasi terbaru bergerak dengan cepat. Kehadiran teknologi dan informasi harus disertai dengan kemampuan manusia. Kemampuan untuk menggunakan dengan baik dan mampu memfilter informasi yang baik. Kecanggihan teknologi dan kecepatan informasi seyogianya disertai dengan kemampuan untuk menggunakannya. Dengan tujuan agar mampu menggunakan berbagai produk-produk teknologi dalam kegiatan pembelajaran. Dengan demikian, guru mampu mengajar menggunakan produk teknologi seperti e-book, animasi, slide dan video. Namun berbagai peluang manusia menggunakan produk teknologi untuk membuat sesuatu yang bertentangan dengan niat baik penemuan teknologi dan informasi. Untuk itu, setiap pengguna teknologi dan informasi harus memperoleh pendidikan sebelum dan ketika menggunakan teknologi dan membaca informasi.
\end{abstract}

Kata Kunci : gadget, teknologi, pendidikan
Profil Penulis Agus Salim

Pendidikan Agama Islam, STAI Syekh H. Abdul Halim Hasan Al Ishlahiyah Binjai Jl. Ir. H. Juanda - Binjai

Korespondensi:

Email: agusasahan40@gmail.com
Reviewing Editor

Swarmilah Hariani, Universitas Mercu Buana, Jakarta

\section{PENDAHULUAN}

Fakta yang terjadi dalam kehidupan saat ini adalah berkembangnya teknologi dan informasi dalam berbagai aspek kehidupan manusia. Berbagai aktifitas kehidupan manusia secara perlahan digantikan robot atau mesin. Durasi memproduksi kebutuhan manusia semakin cepat karena semakin bertambahnya populasi manusia.

Berbagai informasi dari berbagai belahan dunia dengan cepat dan mudah diakses siapapun dan kapapun. Inilah yang disebut dengan dunia tanpa batas. Kehidupan individu dan negara tidak bisa menutup diri karena derasnya kemajuan informasi dan ditambah adanya media online dan media sosial. Setiap aktivitas kehidupan pribadi dan orang lain dishare menggunakan satu atau lebih media sosial yang dimiliki. Sedangkan orang lain dengan mudah mengetahui kegiatan dan privasi orang lain.

Kecanggihan teknologi dan informasi memaksa masyarakat untuk mengubah kebiasaan dan membuat suatu tradisi baru dalam berbagai aspek kehidupan manusia. Baik dalam aspek ekonomi, kesehatan, dan pendidikan. Kehadiran teknologi dan informasi bertujuan untuk memudahkan manusia melakukan berbagai aktivitas manusia. Namun 
kebaikan dan kemudahan yang ditawarkan teknologi dan informasi disalahartikan dan disalahgunakan sebagian masyarakat. Sehingga produk-produk teknologi teknologi dan informasi hanya digunakan terbatas untuk kepentingan hiburan saja. Lebih dari itu, ada yang menggunakan teknologi dan informasi untuk membuat konten asusila dan membuat serta menyebarkan berita yang belum diketahui benar atau tidaknya. Lalu masyarakat khusus anak-anak dalam usia produktif menjadi korban dari konten dan informasi. Akibat dari hal ini adalah esensi teknologi dan informasi berubah ke arah yang tidak baik sehingga merubah paradigma masyarakat terhadap teknologi. Teknologi dan informasi bukan sebagai malaikat penyelamat kehidupan masyarakat tetapi menjadi hantu yang menakutkan.

\section{Sasaran Kegiatan}

Sasaran kegiatan ini adalah kepada masyarakarat ibu rumah tangga desa Pematang Tengah. Harapan dari kegiatan penyuluhan ini adalah agar para ibu rumah tangga dapat memiliki informasi, pengetahuan, dan perkembangan penggunanaan gadget. Sehingga para ibu rumah tangga dapat mengedukasi dan mengawasi anak-anak dalam menggunakan gadget.

\section{Masalah yang ingin dipecahkan}

Kehadiran gadget pada dasarnya adalah untuk memudahkan segala urusan dan memperoleh berbagai informasi dan pengetahuan. Namun penggunaan gadget terbatas untuk hiburan sehingga anak-anak lalai mengerjakan tugas sekolah, tugas rumah dan enggan untuk bersosialisasi.

\section{MATERI DAN METODE}

Kegiatan ini dilaksanakan besertaan dengan kegiatan Kuliah Kerja Nyata (KKN) mahasiswa STAI Syekh H. Abdul Halim Hasan Al Ishlahiyah Binjai. KKN dilaksanakan dari 3 Agustus-3 September 2021 yang berlokasi di Desa Pematang Tengah, Kecamatan Tanjung Pura, Kabupaten Langkat Prov. Sumatera Utara. Materi yang disampaikan adalah tentang pengenalan gadget, manfaat, dampak positif dan negatif terhadap kehidupan. Metode yang digunakan dalam kegiatan ini adalah metode ceramah yang disampaikan pada kegiatan/acara rutin keagamaan, wirid yasin. Sedangkan pematerinya adalah Agus Salim, S.Pd.I., M.Pd.I.

\section{HASIL DAN PEMBAHASAN}

Teknologi merupakan sistem yang diciptakan oleh manusia untuk suatu tujuan tertentu. Ia merupakan perpanjangan dari kemampuan manusia. Ia dapat kita pakai untuk menambah kemampuan kita untuk menyajikan pesan, memproduksi barang lebih cepat dan lebih banyak, memproses data lebih banyak, memberikan berbagai macam kemudahan, serta untuk mengelola proses maupun orang (Yusufhadi Miarso, 2016). Jadi, teknologi merupakan hasil dari kemampuan manusia untuk memberikan kemudahan untuk memenuhi kebutuhan manusia. Teknologi dapat dibedakan menjadi dua macam. Yang pertama dan lazim kita kenal adalah teknologi fisik atau mekanik yang ditandai oleh mesin, alat, dan perangkatnya. Yang kedua kurang sekali dikenal sebagai teknologi, yaitu teknologi sosial yang merupakan tatanan atau acuan yang ditetapkan oleh orang lain dalam mengorganisasikan manusia dan lingkungannya, serta hal-hal yang mengatur tugas, fungsi, wewenang dan kekuasaan (Miarso, 2016).

Kemudahan yang diberikan teknologi dan informasi dalam pendidikan dapat dimanfaat oleh guru dan anak murid. Guru dan siswa dapat menggunakan fasilitas google book untuk menambah pengetahuan. Guru dapat memanfaatkan google form untuk absen kehadiran, 
penilaian, evaluasi, dan kuesioner untuk kegiatan penelitian. Guru dapat memanfaatkan video, aplikasi, dan animasi dalam mengajarkan materi ajar kepada siswa.

Bila kita sadar, bahwa era pembelajaran saat ini adalah era pembelajaran berbasis aneka sumber; maka sudah seharusnya kita melepaskan kebiasaan menggunakan sumber belajar tertentu saja. Selain tidak efektif, proses pendistribusian sumber belajar (buku pelajaran), terkesan lambat, dan mahal. Sebab ada kemungkinan adanya keterbatasan jumlah, dan ongkos kirim yang relatif besar dibandingkan dengan mengirim emal. Pertimbangan menggunakan layanan informasi yang cepat dan murah, haruslah sudah menjadi pemikiran kita saat ini. Beranilah membuka diri terhadap masuknya TIK dalam profesi yang kita jualankan selama ini (Prawiradilaga et al., 2016).

Media sosial tidak saja digunakan untuk kampanye politik tetapi media sosial digunakan untuk mengkampanyekan kebaikan-kebaikan. Kemajuan teknologi terbaru, khususnya teknologi pendidikan telah menghasilkan hasil positif di sektor pendidikan. teknologi pendidikan baru ini mendukung proses pengajaran dan pembelajaran, teknologi telah mendigitalkan ruang kelas melalui alat pembelajaran digital seperti, komputer, iPad, smart phone, papan tulis digital pintar, dengan teknologi tersebut dapat meningkatkan keterlibatan dan motivasi siswa terhadap pembelajaran (Akbar Iskandar et al., 2020).

Untuk menggunakan berbagai fasilitas yang terkait pembelajaran harus dibarengi dengan kemampuan. Untuk itu, berbagai pelatihan penggunaan media pembelajaran berbasis digital banyak dijumpai dalam berbagai flyer di grup media sosial berbasis pendidikan. Untuk itu, setiap yang bergelut dalam dunia pendidikan harus memanfaatkan kesempatan meningkatkan kompetensi digital khususnya guru. Oleh karena anak didik hidup dalam dunia yang berkaitan dengan teknologi.

Teknologi tidak mengandung nilai dalam dirinya sendiri; semuanya tergantung bagaimana manusia merancangnya, memanfaatkannya, dan menerimanya. Teknologi yang berhasil meringankan kerja (Yusufhadi Miarso, 2016). Penciptaan teknologi, sesuai dengan esensinya, dilakukan untuk memudahkan dan membantu kegiatan hidup manusia. Walaupun mampu memberikan kontribusi yang positif, dampak dari penciptaan sebuah teknologi sering pula memberi warna negatif terhadap kehidupan manusia (Pribadi, 2017). Teknologi memiliki kemampuan untuk meningkatkan hubungan komunikasi antara guru dan siswa. Teknologi tidak hanya membantu siswa yang berada di perkotaan tetapi juga siswa di desa. Materi pembelajaran saat ini telah sangat berkembang karena berbagai kemajuan teknologi. Ketika guru secara aktif mengintegrasikan teknologi ke dalam bidang pelajaran, guru akan tumbuh menjadi peran penasihat, ahli konten, dan pelatih (Iskandar et al., 2020). Untuk itu, kehadiran teknologi dan informasi membantu berbagai permasalahan guru dan siswa dalam pembelajaran.

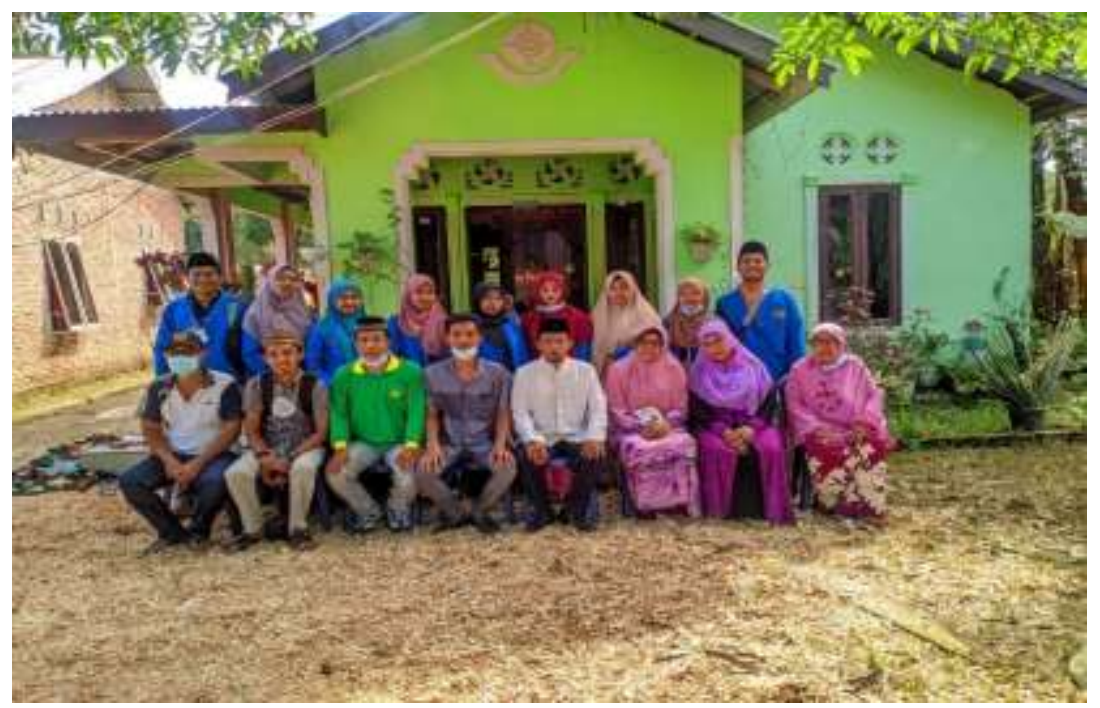

Gambar 1. Dokumentasi kegiatan Pengabdian masyarakat di desa Pematang Tengah 
Produk teknologi dan informasi yang ada penting untuk dimplementasikan dalam dunia pendidikan. Untuk itu, ada beberapa hal yang harus dipersiapkan, yaitu:

Pertama, jaringan internet. Secanggih apapun teknologi dan informasi jika tidak didukung dengan jaringan internet stabil maka masyarakat tidak akan maksimal menggunakan teknologi dan informasi. Untuk hal ini, pemerintah harus memperbaiki infrastruktur internet di seluruh tanah air secara bertahap. Karena pendidikan merupakan hak bagi setiap warga negara dan ketika teknologi dan informasi diimplementasikan dalam pendidikan maka akses internet di setiap daerah harus diperhatikan. Jadi, kebijakan pendidikan berbasis digital harus dibarengi dengan infrastruktur dan fasilitas yang mendukung. Pemerintah wajib mempertimbangkan hal ini agar terwujudnya keadillan bagi seluruh masyarakat.

Kedua, sarana dan prasarana. Implementasi pendidikan menggunakan teknologi dan informasi membutuhkan teknologi seperti laptop/notebook, infokus, loudspeaker, OHP, projektor dan lainnya. Untuk itu, pemerintah, kementerian, pemerintah daerah dan pihak-pihak yang berkepentingan terhadap pendidikan.

Ketiga, skill. Berbagai produk teknologi yang banyak dan canggih harus harus dibarengi dengan kemampuan untuk menggunakannya. Khususnya pendidik atau orang tua yang hidup bukan pada lahirnya teknologi dan informasi digital. Ini menjadi salah satu masalah besar yang dihadapi dunia pendidikan khususnya pendidik. Oleh karena segala kegiatan pendidikan oleh beberapa lembaga sekolah di tanah sudah hijrah kepada pelayananan administrasi berbasis digital, peminjaman buku, dan proses pembelajaran. Berbagai kegiatan webinar yang diselenggarakan Kementerian Informatika dan kementerian, organisasi dan kampus banyak melakukan webinar pelatihan atau tutorial secara offline maupun online. Kegiatan tersebut ada berbayar dan ada yang free. Bagi guru yang memiliki nasib yang baik dapat mengikuti kegiatan pelatihan berbayar maupun free. Sebaliknya, guru juga dapat mengikuti kegiatan pelatihan free.

Keempat, soft-skill. Kemampuan menggunakan teknologi juga dibarengi dengan soft-skill. Hal ini bertujuan mengimbangi agar terhindar dan meminimalisir penyalahgunaan penggunaan teknologi dan informasi. Penyalahgunaan teknologi dan informasi akan merugikan bagi orang yang bersangkutan dan orang lain.

Untuk itu, peran keluarga, sekolah, tokoh masyarakat, tokoh agama dan pemerintah bekerja sama dalam rangka tindakan preventif. Anak-anak tidak boleh diacuhkan menggunakan gadget tanpa ada pengawasan, arahan dan edukasi. Oleh karena semua memiliki kesempatan yang sama dalam menggunakan teknologi dan informasi. Sedangkan pada prinsipnya kehadiran teknologi dan informasi adalah untuk kemudahan dan kebaikan bersama.

\section{Evaluasi kegiatan}

Secara umum pelaksanaan pengabdian kepada masyarakat terlaksana dengan baik. Kegiatan ini terselenggara dengan baik atas inisiatif dan kerja sama dengan mahasiswa KKN, Pemerintah Desa Pematang Tengah, dan masyarakat. Kegiatan terlaksana sesuai waktu dan tempat yang yang dijadwalkan.

\section{Kesimpulan}

\section{KESIMPULAN}

Adanya teknologi dan informasi untuk memudahkan segala aktivitas kehidupan manusia termasuk pendidikan. Guru, orang tua dan siswa dapat memanfaatkan berbagai fasilitas atau produk teknologi sesuai dengan kemampuan yang dimiliki. Guru dapat menggunakan berbagai fasilitas e-book atau referensi yang dapat dipertanggungjawabkan keilmuannya, menggunakan video, animasi, dan aplikasi dalam kegiatan pembelajaran. Siswa juga dapat mencari berbagai 
materi pelajaran selain yang diperolehnya dari guru. Oleh karena banyaknya fasilitas teknologi dan informasi maka perlu ada pengawasan dan edukasi yang diberikan kepada masyarakat khususnya anak didik. Tujuannya adalah agar mereka dapat menggunakan teknologi dengan baik dan menerima informasi dengan bijak.

\section{Saran kegiatan Lanjutan}

Pendidikan utama dan pertama adalah dari rumah tangga. Ayah dan ibu sekaligus sebagai orang tua dan guru dalam rumah. Orang tua memiliki tanggung jawab untuk memperhatikan perkembangan dan kegiatan anak. Untuk itu, hendaknya orang tua dapat mengimplementasikan hasil kegiatan penyuluhan tentang penggunaan gadget dalam rumah tangga. Mengingat masalah ini penting dan menjadi perhatian serius agar pembinaan dan penyuluhan kepada masyarakat terus dilakukan oleh pemerintah, kampus melalui kegiatan pengabdian kepada masayarakat dan berbagai elemen masyarakat.

\section{REFERENSI}

Miarso, Y. (2016). Menyemai Benih Teknologi Pendidikan. Jakarta: Prenadamedia Group, cet. ke-8. Prawiradilaga, D.S. (2016). Mozaik Teknologi Pendidikan E-Learning. Jakarta: Prenadamedia Group, cet. ke-2.

Iskandar, A. (2016). Aplikasi Pembelajaran Berbasis TIK. Yayasan Kita Menulis, cet. I.

Pribadi, B.A. (2017). Media \& Teknologi dalam Pembelajaran. Jakarta: Prenadamedia, cet. Ke-1.

\section{About the Authors}

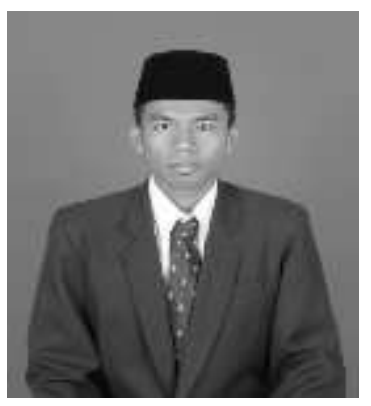

Agus Salim, Kelahiran Kapias Batu VIII, 17 Agustus 1986. Penulis merupakan dosen tetap STAI Syekh H. Abdul Halim Hasan Al Ishlahiyah Binjai Prodi Pendidikan Agama Islam. Penulis menjadi dosen di kampus sejak tahun 2018. Email: agusasahan40@gmail.com

\section{DECLARATIONS}

\section{Funding}

Kegiatan pengabdian kepada masyarakat ini dibiayai oleh Yayasan STAI Syekh H. Abdul Halim Hasan Al Ishlahiyah Binjai melalui LP2M.

\section{Competing Interests}

Penulis menyatakan bahwa tidak ada konflik kepentingan yang diungkapkan. 